Proceedings of the $X$ th International Congress on Photosynthesis, August 1995, Ed. P. Mathis, Kluwer Academic Publishers, 1995

\title{
FROM PHOTONS TO PROTONS IN THE PHOTOCYCLE OF BACTERIAL REACTION CENTER
}

\author{
P. Maróti, Sz. Osváth, Cs. Tápai, D. K. Hanson" and P. Sebban"* \\ JATE University Szeged, Institute of Biophysics \\ Egyetem utca 2. Szeged, Hungary H-6722 \\ "Center Mech. Biol. and Biotechnology, Argonne National Laboratory, Argonne, USA \\ "Centre de Génétique Moleculaire, CNRS, Gif/Yvette, France
}

The submitted manuscript has been created by the University of Chicago as Operator of Argonne National Laboratory ("Argonne") under Contract No. W-31-109-ENG-38 with the U.S. Department of Energy. The U.S. Government retains for itself, and others actIng on its behalf, a paid-up, nonexclusive, Irrevocable worldwide license in said article to reproduce, prepare derivative works, distribute coples to the public, and periorm pubIlcly and display publicly, by or on behalf of the Government.

\section{Introduction}

The membrane bound $R C$ protein plays central role in energetics of photosynthetic bacteria by converting different forms of free energy: light energy into phosphate potential via redox energy and proton electrochemical gradient [1]. The absorption of photons initiates photochemical electron transfer from the excited dimer (P) through a chain of electron acceptor molecules, ultimately reducing the primary and secondary quinones $Q_{A}$ and $Q_{B}$, respectively. The electron transfer is coupled to proton binding by $\mathrm{RC}$ to solvate (stabilize) semiquinone anions $\left(\mathrm{Q}_{\mathrm{A}}^{-}\right.$and $\mathrm{Q}_{\mathrm{B}}{ }^{-}$) and later to reduce $\mathrm{Q}_{B}$ to hydroquinol, $\mathrm{Q}_{B} \mathrm{H}_{2}$ [2]. The doubly reduced quinone dissociates from the $R C$ and is reoxidized by the cytochrome $b_{1}$ complex. The vectorial transport of protons from the cytoplasmic to the periplasmic side of the membrane builds up proton electrochemical gradient which drives ATP synthesis.

Proton transport is a key process in utilization of light energy. Some proton transport proteins, e.g. bacteriorhodopsin pump protons directly through the dielectric core of the biological membrane. On the other hand, photosynthetic organisms use indirect way by decreasing the energetic barrier of the membrane for the protons: electrons will be transported through the membrane via redox chain and form subsequently electrically neutral species with the $\mathrm{H}^{+}$-ions. Thus the protons can pass the membrane with significantly less penalty. The photosynthetic electron transport can be viewed as accessory step that prepare the RC for protonation. Taking this point of view, it is surprising that much less effort has been placed on the proton transport than on electron transfer reactions in RCs.

In this work special emphasis will be put on energetics and kinetics of proton binding to $R C$ as primary step in bacterial proton transport. The results of site-directed mutagenesis and structure-based electrostatic calculations will help us to understand the electrostatic role of the protein in proton binding and the possible pathways of $\mathrm{H}^{+}$-ions to $\mathrm{Q}_{\mathrm{B}}$. The $\mathrm{pH}$-dependence of the rate of the photocycle will be used to demonstrate how the limitations of quinone/quinol exchange and protonation become the bottleneck of the photocycle in the neutral and allkaline $\mathrm{pH}$-ranges under intense continuous illumination.

\section{Methods}

The details of construction of mutants and measurements of electron and proton transfer characteristics were performed as described in cited references.

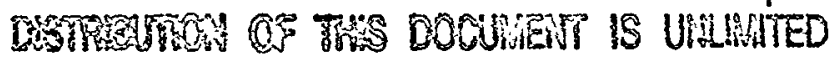

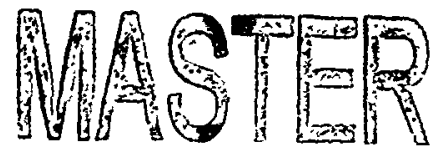




\section{DISCLAIMER}

Portions of this document may be illegible in electronic image products. Images are produced from the best available original document. 


\section{DISCLAIMER}

This report was prepared as an account of work sponsored by an agency of the United States Government. Neither the United States Government nor any agency thereof, nor any of their employees, make any warranty, express or implied, or assumes any legal liability or responsibility for the accuracy, completeness, or usefulness of any information, apparatus, product, or process disclosed, or represents that its use would not infringe privately owned rights. Reference herein to any specific commercial product, process, or service by trade name, trademark, manufacturer, or otherwise does not necessarily constitute or imply its endorsement, recommendation, or favoring by the United States Government or any agency thereof. The views and opinions of authors expressed herein do not necessarily state or reflect those of the United States Government or any agency thereof. 
The program DELPHI, a generous gift from Dr. Barry Honig, Columbia University, New York was used to solve the Poisson-Boltzmann equation for the electrostatic potential in and around the RC. The coordinates were taken from the Brookhaven Protein Data Bank (structure 4RCR, date 09-SEP-91, resolution $2.8 \AA$ ).

Electrostatic profile of the RC

The electrostatic field of the RC was calculared using classical electrostatics as in $[3,4]$. Figure 1 demonstrates the electrostatic contour levels of $2 . \mathrm{kT} / \mathrm{e}(\approx 50 \mathrm{mV})$ in a two-dimensional slice through the main cofactors of $P, Q_{A}$ and $Q_{B}$ at low and high $\mathrm{pH}$ values. Negative potential is represented by dashed lines and positive potential by solid lines. The surface of the protein is indicated by a heavy solid line. The electrostaric field drives the $\mathrm{H}^{-}$-ions from the bulk phase to the interior of the protein upon light excitation.

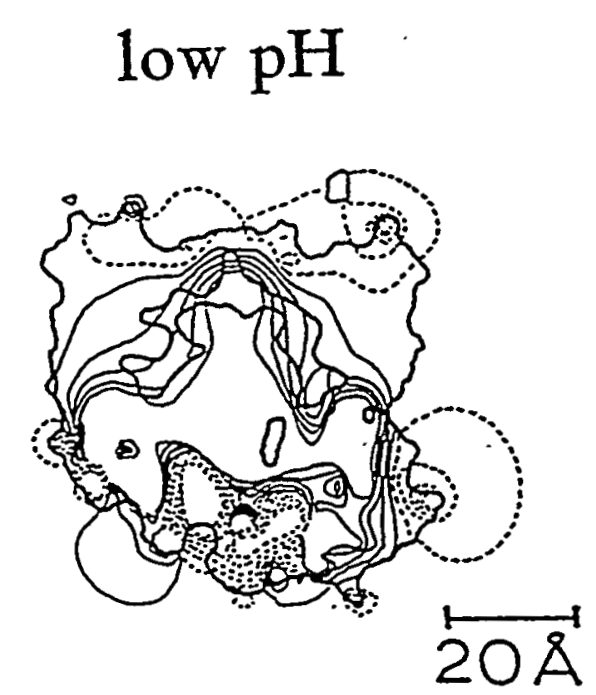

$$
\text { : high } \mathrm{pH}
$$

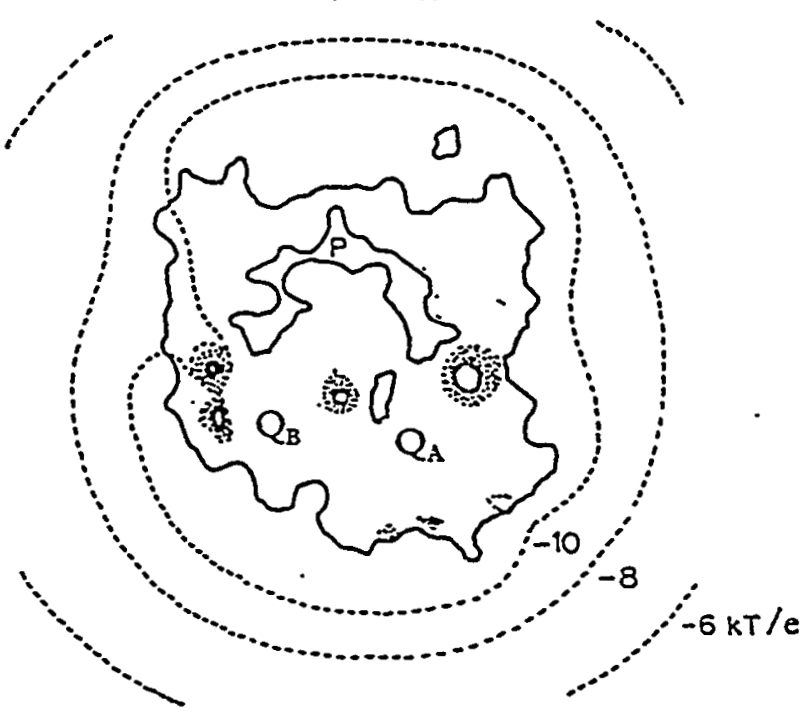

Figure 1 Electrostatic profile of RC at low (Glu and Asp are negatively and His, Lys and Arg positively charged) and high (Glu, Asp, Cys and Tyr are negatively and Arg positively charged) $\mathrm{pH}$ values.

The clusters of acidic residues around $Q_{g}$ binding pocket produce increasing negative surface potential by alkalization of the solution and in some places, the focusing of the electric field in the $Q_{B}$ pocket can be observed. These effects will facilitate the uptake $\mathrm{H}^{+}$-ions by the $\mathrm{RC}$ in the alkaline $\mathrm{pH}$ range where the concentration of $\mathrm{H}^{+}$-ions and thus the rate of bimolecular collision with the protein dramatically decreases.

Proton uptake due to solvation of semiquinone anions

The light-generated anion radical species, $Q_{A^{-}}$and $Q_{B}$, are effectively solvated by the protein. The anionic charges induce $\mathrm{pK}_{2}$ shifts in ionizable side-chain groups of various amino acid residues (see above for calculation). The differential compensation of the two semiquinone charges, which includes proton binding by the protein, provides much of the driving force for transfer of the first electron from $Q_{A}{ }^{-}$to $Q_{B}$. Studies of site-specific mutants have identified Glu 
the charged forms of the quinones and also appear to interact electrostatically with each other: the ionization of Asp L213 suppresses the ionization of Glu L212, which has an unusually high $\mathrm{pK}_{\mathrm{z}} \approx 9.6$. Electron and proton transfer in the quinone acceptor complex could be partially accounted for by a simple electrostatic model of interacting Glu L212 and Asp I213, and $Q_{3}$ $[12,13]$. Protonation of the two amino acids under acidic (Asp L213) and alkaline (Glu L212) conditions determine the $\mathrm{pH}$ dependence of the one-electron equilibrium constant of electron transfer from $Q_{A}{ }^{-}$to $Q_{B}[2,4,14,15]$.

Recent studies on flash-induced proton binding stoichiometry of RCs with substituted quinones at the primary quinone binding site indicated the possible contribution of Tyr $\mathrm{H} 40$ in the stabilization of the primary semiquinone [16]. Glu L212 has been identified by time resolved and steady state infrared spectroscopy and significant protonation of Glu L212 has been shown at $\mathrm{pH}$ region well below its proposed $\mathrm{pK}_{2}$ value (e.g. $\approx 0.5 \mathrm{H}^{+} / \mathrm{RC}$ at $\mathrm{pH}$ 7) [17]. It was concluded that the $\mathrm{pH}$ behaviour of Glu L212 could not be explained by the titration of a single isolated residue, but the titration must be unusually broad due the strong interaction with other charged groups in the $\mathrm{Q}_{\mathrm{B}}$ site $[3,4]$.

These observations call for re-examination of measurements on $\mathrm{pH}$ dependence of electron and proton transfer in RCs of wild type and mutants and revision of the interpretation in terms of the key residues. The responsibility of Asp L213 is also unclear probably due to the location of this residue as parr of the acidic charge-cluster involving Asp I210 and Arg I217, amongst others, providing the potential for strong interactions between these groups [6]. The charge cluster can be studied by mutation of protonatable residues for non-protonatable groups. The effect of substituting lysine for Glu L212 is exceptionally interesting as the expected large effects of a net positive charge were not seen and the quinone function was not greally impaired [18]. Lys L212 may form charge pair with a residue other than Asp I213.

The results from IR measurements require a better understanding of the electrochromic shift of bacteriopheophytins that have been used for tracking interquinone electron transfer. The measured absorption change contains components both from electron transfer and from ionic (proton) relaxation around the quinones [19-21]. Separation of these events is of great importance. One possible way is the observation of dimer fluorescence. The yield of fluorescence of the dimer in the $R C$ is highly dependent on the redox state of the RC: it is high in the closed $\left(P Q_{A} Q_{B}\right)$ and low in the open $\left(P Q_{A} Q_{B}{ }^{\circ}\right.$ state. The yield of fluorescence is much more sensitive to the position of the electron in the quinone complex than to the ionic configuration in the surroundings, thus the kinetics of the electron transfer will control the yield of dimer fluorescence [see 22].

The study of kinetics of proton binding accompanying semiquinone formation has revealed that much of the $\mathrm{H}^{+}$-ion uptake appeared to be directed at residues that were not immediately accessible, and the kinetics of proton binding were not simply limited by diffusion of proton donor species $[23,24]$. In $\mathrm{D}_{2} \mathrm{O}$, little or no solvent isotope effect was observed at $\mathrm{pH} / \mathrm{D}=7$, but the ratio of rate constants of proton binding $\left(k_{\mathrm{H}} / k_{\mathrm{D}}\right)$ increased to about 3 at higher $\mathrm{pH}$. The kinetic behaviour implied rate-limiting intraprotein proton transfer to specific buried residues in the protein matrix.

\section{Proton delivery pathways to $Q_{B}$}

After the second light-driven electron transfer $Q_{B} \mathrm{H}_{2}$ is formed, and net proton uptake from the aqueous phase must occur. The proton delivery pathway to the quinone head group involves several ionizable amino acid residues in and around the $Q_{B}$ pocker. Analysis of sitedirected mutants indicated the activity of two terminal pathways for proton delivery to $Q_{3}$. 
One of them involves Ser L223 through Asp L213, whereas the other involves Glu L212 via possibly Asp L213 [2]. Recent Monte Carlo calculations [25] and high resolution X-ray data [26] reveal water molecules located around the $Q_{B}$ site; their involvement in proton delivery is also likely. Proton uptake measurements of RC films with variable water content would certainly reveal the importance of bound and mobile water molecule in proton transfer.

Not only internal water molecules but subtle structural changes can contribute to proton delivery. Voids which can also be created by mutations, can be filled by water molecules facilitating the transport of $\mathrm{H}^{+}$-ions in the interior of the protein. Their effect (together with the possible modification of the $\mathrm{H}$-bond network of internal water molecules and protonatable amino acid residues) was studied by double mutants and revertants. It was shown that the compensation mutations (second site revertants) can occur far away from $Q_{3}[11,27]$ indicating the central role of long-range electrostatic interaction in function of the protein [15,28].

\section{Limitation of proton uptake under continuous illumination}

The vast majority of kinetic and energetic data have been obtained from flash kinetic measurements. From physiological point of view, it could be interesting to see how these results will predict the electron and proton transfer characteristics observed under continuous

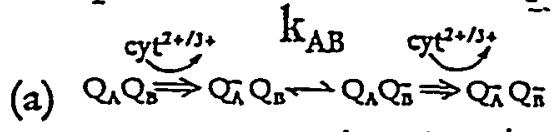

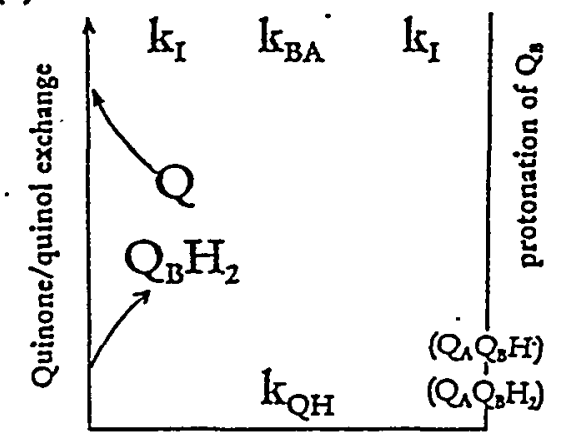

(b)

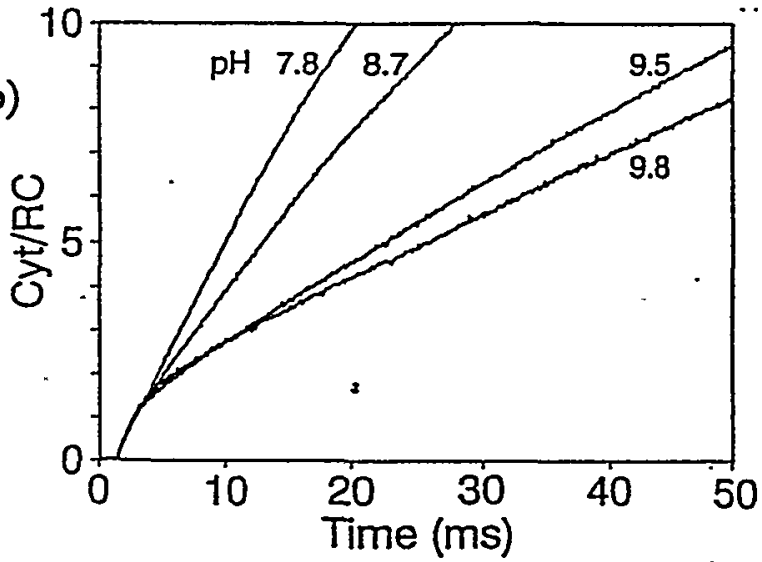

Figure 2 Scheme of photocycle under continuous illumination (a) and cytochrome photooxidarion at different $\mathrm{pH}$ values $\left(\mathrm{k}_{\mathrm{f}}=2.10^{3} \mathrm{~s}^{-1}\right)$.

illumination.

The photocycle under stacionary conditions can be modelled by two light and dark reactions alternatively connected in series (Fig. 2a). The rates of the two light reactions $\left(\mathrm{k}_{\mathrm{f}}\right)$ are equal, $k_{A B}$ and $k_{B A}$ represent the rates of forward and back reactions in semiquinone equilibration, respectively, and $\mathrm{k}_{\mathrm{QH}}$ denotes the apparent rate of protonation of $\mathrm{Q}_{B}$ and quinone/quinol exchange which depends on the nature of the quinone and detergent. The photocycle can be tracked either by observation of cytochrome oxidation or proton binding. The initial rate is $k_{I}$ which decreases to a stacionary value of

$$
k_{a b s}=\frac{k_{I}}{1+\frac{k_{I}}{2} \cdot\left(\frac{1}{k_{O A}}+\frac{1}{k_{A B}}\right)+\frac{k_{B A}}{2 \cdot k_{A B}}}
$$


(a)

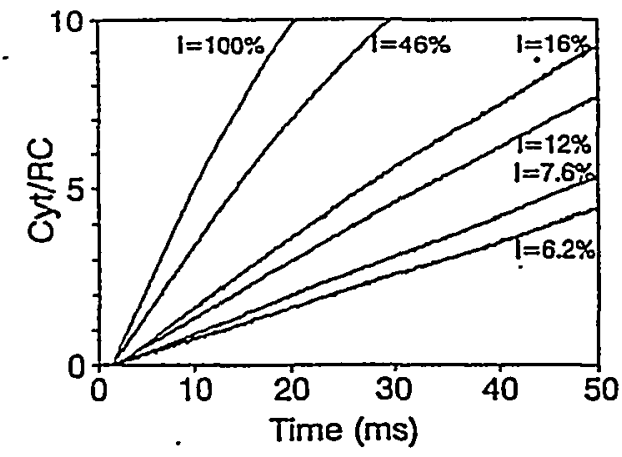

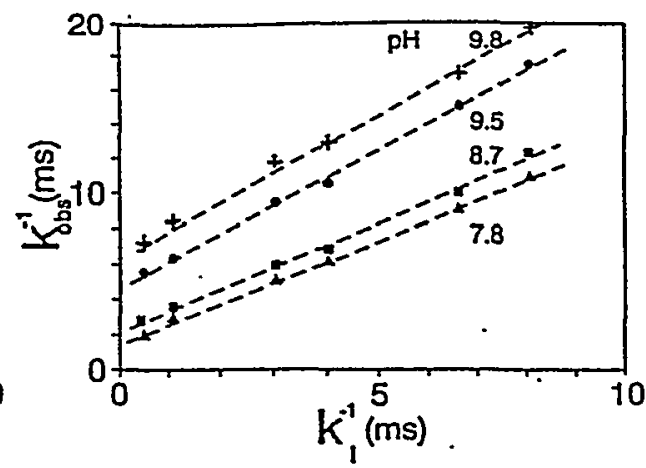

(b)

Figure 3 Cytochrome photooxidation at different light intensities (a) and double reciprocal plot to determine $\mathrm{k}_{\mathrm{QH}}$ according to Eq. (1) (b).

after a transient period much longer than the slowest step in the photocycle (Fig. $2 b$ ). If $\mathrm{k}_{\text {obs }}$ is measured under different light intensities (Fig. 3a), $\mathrm{k}_{\mathrm{QH}} \mathrm{can}$ be derived from interception of a double reciprocal plot $\left(\mathrm{k}_{\mathrm{bbs}}{ }^{-1}\right.$ vs. $\left.\mathrm{k}_{\mathrm{I}}{ }^{-1}\right)$ (Fig. $3 \mathrm{~b}$ ). According to Fig. $4, \mathrm{k}_{\mathrm{QH}}$ is limited by the rate of quinone/quinol exchange below $\mathrm{pH} 7$ and by the rate of protonation in the alkaline $\mathrm{pH}$ range.

Inspection of the X-ray structure, the isoprenoid tail of the ubiquinone paves the. way for the head group at dissociation from the RC. An aliphatic residue on the I subunit, Ieu L232, is positioned close to the tail of $Q_{B}$ in such a way that it may regulate the diffusion of the quinone/quinol into and out of the RC. The equivalent amino acid on the $Q_{A}$ site is $\operatorname{Trp} M 266$, the indole ring of which interacts with the tail of the primary quinone and could prohibit the release of $Q_{A}$ under physiological conditions. Measurement of quinone/quinol exchange rate of site-directed mutants at Leu I232 would bring us closer to understanding the export of reducing equivalents from RC at molecular (atomic) level.

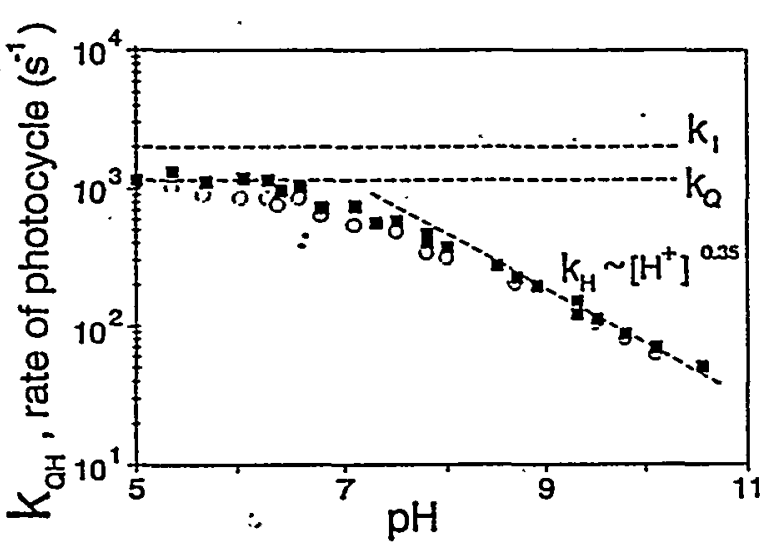

Figure 4 PF-dependence of the rate of photocycle.

\section{CONCLUSIONS}

The detailed knowledge of the atomic coordinates of the bacterial RCs has permitted a close scrutiny of structure/function relationships not only of the quinones but of the protein itself with its internal water structure. Protonatable groups were identified as intrinsic part of the redox reactions, providing charge compensation (important for semiquinone formation) and forming channels for the movement of $\mathrm{H}^{+}$-ions. to $\mathrm{Q}_{B}{ }^{2}$. The nature and position of these groups give rise to electrostatic profile that determines the kinetics and energetics of proton transport. Fine tuning or dramatic variations of proton delivery pathways can adapt the photocycle to changes in bulk phase $\mathrm{pH}$ values, buffering capacities and primary structure (mutations) of the reaction center. 
ACKNOWLEDGEMENTS: This work was supported by the Hungarian Science Foundation (OTKA 17362/95), Balaton project (NP-715/95-F), Foundation for Hungarian Education and Research (FEFA III 1034) and International Human Frontier Science Program (RG-329/95 M).

\section{REFERENCES}

1 Nicholls, D.G. and Ferguson, S.J. (1992) Bioenergetics 2, Acad. Press, H. Brace Jovanovich, Publishers

2 Okamura, M.Y. and Feher, G. (1992) Annu. Rev. Biochem. 61, 861-896

3 Gunner, M. and Honig, B. (1992) in The Photosynthetic Bacterial Reaction Center (Breton J. and Vermeglio A., eds.) pp. 403-410, Plenum Press, New York

4 Beroza, P., Fredkin, D., Okamura, M.Y. and Feher, G. (1995) Biophys. J. 68, 2233-2250

5 Paddock, M.L., Rongey, S.H., Feher, G. and Okamura, M.Y. (1989) P. Nacl. Acad. Sci. 86, 6602-6606

6 Paddock, M.L., Rongey, S.H., McPherson, P.H., Juth, A., Feher, G. and Okamura, M.Y. (1994) Biochemistry 33, 734745

7 Takahashi, E. and Wraight, C.A. (1990) Biochim. Biophys. Acta 1020, 107-111

8 Takahashi, E. and Wraight, C.A. (1991) FEBS Ietters 283, 140-144

9 Takahashi, E. and Wraight, C.A. (1992) Biochemistry 31, 855-866

10 McPherson, P.H., Schönfeld, M., Paddock, M.L., Okamura, M.Y. and Feher, G. (1994) Biochemistry 33, 1181-1193

11 Maróti, P., Hanson, D.K., Baciou, I., Schiffer, M. and Sebban, P. (1994) PNAS 91(12), 5617-5621

12 Shinkarev, V.P., Takahashi, E. and Wraight, C.A. (1992) in The Photosynthetic Bacterial Reaction Center II. Structure, Spectroscopy and Dynamics (Breton J. and Vermeglio A., eds.) pp. 375-387, Plenum Press, New York

13 Shinkarev, VP. and Wraight, C.A. (1993) in The Photosynthetic Reaction Center (Deisenhofer J. and Norris J., eds.) Vol 1, pp. 193-255, Academic Press, New York

14 Baciou, L., Bylina, E.J. and Sebban, P. (1993) Biophys. J. 65, 652-660.

15 Sebban, P., Maróti, P. and Hanson, D.K. (1995) Biochimie (in press)

16 Kálmán, I and Maróti, P. (1994) Biochemistry 33, 9237-9244

17 Fienerwalder, R, Grzybek, S., Fogel, C., Kreutz, W., Okamura, M.Y., Paddock, M., Breton, J., Nabedryk, E. and Mantele, W. (1995) Biochemistry 34, 2832-2843

18 Takahashi, E., Shinkarev, V.P., Maróti, P. and Wraight, C.A. (1992) in: "Structure, Function and Dynamics of the Bacterial Reaction Center" (eds. Breton J and Vermeglio A) NATO workshop, Cadarache pp 63-64.

19 Brzezinski, P., Okamura, M.Y. and Feher, G. (1992) in The Photosynthetic Bacterial Reaction Center II. (Breton J. and Vermeglio A., eds.) pp. 321-330, Plenum Press, New York

20 Tiede, D.M. and Hanson, D.K. (1992) in The Photosynthetic Bacterial Reaction Center II. Structure, . Spectroscopy and Dynamics (Breton J. and Vermeglio A., eds.) pp. 342-350, Plenum Press, New York

21 Kálmán, I., Turzó, K. and Maróti, P. (1993) Photosynthetica 28(2), 185-194

22 Osváth, Sz., Laczkó, G., Sebban, P. and Maróti, P. (this Proceedings)

23 Maróri, P. and Wraight, C.A. (1989) Biophys. J. 55, 428a

24 Takahashi, E., Maróti, P. and Wraight, C.A. (1992) in Electron and Proton Transfer in Chemistry and Biology (Diemann E. ed.) pp. 219-236 Elsevier Publ. Amsterdam

25 Beroza, P., Fredkin, D., Okamura, M.Y. and Feher, G. (1992) in The Photosynthetic Bacterial Reaction Center II. (Breton J. and Vermeglio A., eds.) pp. 363-374, Plenum Press, New York -

26 Ermler, U., Michel, H. and Schiffer, M. (1994) J. Bioenergetics Biomembranes 26, 5-15

27 Hanson, D.K., Baciou, L., Tiede, D.M., Nance, S.L., Schiffer, M. and Sebban, P. (1992) Biochim. Biophys. Acta 1102, 260-265

28 Sebban P., Maróti, P., Schiffer, M. and Hanson, D.K. (1995) Biochemistry 34, 8390-8397 